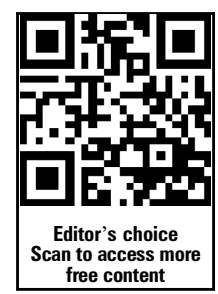

ORIGINAL ARTICLE

\title{
Juvenile myelomonocytic leukaemia and Noonan syndrome
}

\author{
Marion Strullu, ${ }^{1,2}$ Aurélie Caye, ${ }^{1,2}$ Julie Lachenaud, ${ }^{1,2}$ Bruno Cassinat, ${ }^{1,3}$ \\ Steven Gazal, ${ }^{4}$ Odile Fenneteau, ${ }^{5}$ Nathalie Pouvreau, ${ }^{2}$ Sabrina Pereira, ${ }^{2}$ \\ Clarisse Baumann, ${ }^{2}$ Audrey Contet, ${ }^{6}$ Nicolas Sirvent, ${ }^{7}$ Françoise Méchinaud, ${ }^{8}$ \\ Isabelle Guellec, ${ }^{9}$ Dalila Adjaoud, ${ }^{10}$ Catherine Paillard, ${ }^{11}$ Corinne Alberti, ${ }^{12,13}$ \\ Martin Zenker, ${ }^{14}$ Christine Chomienne, ${ }^{1,3}$ Yves Bertrand, ${ }^{15}$ André Baruchel, ${ }^{16}$ \\ Alain Verloes, ${ }^{2,17}$ Hélène Cavé ${ }^{1,2}$
}

\begin{abstract}
- Additional material is published online only. To view please visit the journal online (http://dx.doi.org/10.1136/ jmedgenet-2014-102611).
\end{abstract}

For numbered affiliations see end of article.

\section{Correspondence to} Dr Hélène Cavé, UF de Génétique Moléculaire, Hôpital Robert Debré, 48, Boulevard Sérurier, Paris 75019, France; helene.cave@rdb.aphp.fr

Received 26 June 2014 Revised 18 July 2014 Accepted 21 July 2014 Published Online First 5 August 2014

\section{CrossMark}

To cite: Strullu M, Caye $\mathrm{A}$ Lachenaud J, et al. J Med Genet 2014;51:689-697.

\begin{abstract}
Background Infants with Noonan syndrome (NS) are predisposed to developing juvenile myelomonocytic leukaemia (JMML) or JMML-like myeloproliferative disorders (MPD). Whereas sporadic JMML is known to be aggressive, JMML occurring in patients with NS is often considered as benign and transitory. However, little information is available regarding the occurrence and characteristics of JMML in NS.
\end{abstract}

Methods and results Within a large prospective cohort of 641 patients with a germline PTPN11 mutation, we identified MPD features in $36(5.6 \%)$ patients, including 20 patients (3\%) who fully met the consensus diagnostic criteria for JMML. Sixty percent of the latter (12/20) had severe neonatal manifestations, and 10/20 died in the first month of life. Almost all (11/ 12) patients with severe neonatal JMML were males. Two females who survived MPD/JMML subsequently developed another malignancy during childhood. Although the risk of developing MPD/JMML could not be fully predicted by the underlying PTPN11 mutation, some germline PTPN11 mutations were preferentially associated with myeloproliferation: 10/48 patients with NS (20.8\%) with a mutation in codon Asp61 developed MPD/JMML in infancy. Patients with a p.Thr73lle mutation also had more chances of developing MPD/ JMML but with a milder clinical course. SNP array and whole exome sequencing in paired tumoral and constitutional samples identified no second acquired somatic mutation to explain the occurrence of myeloproliferation.

Conclusions JMML represents the first cause of death in PTPN11-associated NS. Few patients have been reported so far, suggesting that JMML may sometimes be overlooked due to early death, comorbidities or lack of confirmatory tests.

\section{INTRODUCTION}

Noonan syndrome (NS, OMIM 163950) is a relatively common (1/2000 births) developmental disorder characterised by reduced postnatal growth, congenital heart defects and cardiomyopathy, variable cognitive deficits, and distinctive facial dysmorphism. ${ }^{1}$ NS patients have an increased risk of developing several types of childhood malignancies, ${ }^{2}{ }^{3}$ including myeloproliferative disorders
(MPD) resembling juvenile myelomonocytic leukaemia (JMML). ${ }^{4}$

MPDs are clonal haematopoietic diseases associating variable degrees of myeloproliferation of different cell lineages. ${ }^{5}$ JMML is a rare and aggressive myelodysplastic and myeloproliferative neoplasm of early childhood, associated with excessive monocytic and macrophagic proliferation. ${ }^{6}{ }^{7}$ Patients typically present with splenomegaly, monocytosis, anaemia, thrombocytopenia and elevated fetal haemoglobin $(\mathrm{HbF})$. Myelograms reveal less than $20 \%$ of myeloblasts, and varying degrees of aberrant myelopoiesis or megakaryopoiesis. ${ }^{8}$ A hallmark of JMML is the hypersensitivity of myeloid progenitors to granulocyte-macrophage colony-stimulating factor (GM-CSF). ${ }^{9}$ Sporadic JMML is usually aggressive and has a poor prognosis. The only curative treatment is allogeneic bone marrow transplantation, with a relapse rate of 30 $40 \%$. By contrast, previous reports have suggested that NS-related JMML is often benign and resolves spontaneously. ${ }^{4}{ }^{10-14}$ However, these reports mainly rely on single or retrospective cases.

In NS and JMML, disease-causing mutations target various genes of the RAS/MAPK pathway. ${ }^{15}{ }^{16}$ With heterozygous germline-activating missense mutations in up to $40 \%$ of cases, PTPN11 (MIM 176876) is the most commonly involved gene in NS. ${ }^{17}$ Most patients with NS and MPD harbour a PTPN11 mutation, ${ }^{14}{ }^{18}$ and about $35 \%$ of sporadic JMML cases display an acquired somatic PTPN11 mutation. ${ }^{19}$

PTPN11 encodes the cytoplasmic phosphatase SHP2, which enhances the signal transduction of growth factors and cytokines by upregulating RAS/ MAPK pathway activation. A functional classification of PTPN11 mutations has been proposed, based on their predicted consequence on SHP2 function. ${ }^{20-22}$ Most PTPN11 mutations found in NS and sporadic leukaemia affect residues located close to or within the N-SH2/PTP interaction domain and disrupt the autoinhibition of the catalytic domain, increasing the basal and/or stimulated phosphatase activity of SHP2. ${ }^{21} 23$

The department of Genetics of Robert-Debré hospital collects the majority of molecularly confirmed French NS patients, and is the reference laboratory for JMML in France. This privileged 
situation prompted us to investigate the incidence of MPDs in a large cohort of patients with NS. This study allowed us to estimate the overall incidence of haematological abnormalities in these children, describe their natural history, and discuss phenotype/genotype correlations.

\section{PATIENTS AND METHODS Patients}

Patient samples were referred to the lab either for suspicion of NS or suspicion of JMML (figure 1). Written informed consent of the parents was obtained according to the declaration of Helsinki.

Between 2002 and 2012, we identified a PTPN11 mutation in leukaemic cells in 52/110 (47\%) patients referred for JMML diagnosed according to international consensus guidelines. ${ }^{8}$ Among them, 20 had a diagnosis of NS based on published diagnostic criteria, ${ }^{24}$ reviewed by expert clinical geneticists (AV, CB). The clinical diagnosis was confirmed in 19/20 cases either directly by demonstrating a PTPN11 mutation in germline (nonhaematopoietic) DNA, or indirectly by identifying a PTPN11 mutation in one of the parents $(n=2)$. These patients were referred as the NS-JMML group. The remaining 32 patients with no clinical signs of NS and no constitutional PTPN11 mutation were designated as the sporadic JMML group (figure 1).

During the same period of time, we identified a germline PTPN11 mutation in 641 probands referred for molecular confirmation of NS, who represented the NS-PTPN11 group considered in this study. Clinical notes for NS patients (prenatal events, growth, malformations, developmental milestones...) were routinely collected on a printed form filled by the clinicians. The clinical form included, among others features, the presence of hepatomegaly or splenomegaly, and the presence of an abnormal blood count.

We focused on NS-PTPN11 patients presenting with splenomegaly, hepatomegaly and/or thrombocytopenia. Clinicians and biologists in charge of patients presenting with at least one of these signs were secondarily contacted for further details.
Hyperleukocytosis $>15 \times 10^{9} / \mathrm{L}$ with sustained monocytosis $>1 \times 10^{9} / \mathrm{L}$ for at least four consecutive weeks, unrelated to infection, was confirmed in 16 patients. These patients showed myeloproliferation but did not fully meet the diagnostic criteria for JMML. They are hereafter referred to as NS-MPD patients (figure 1). DNA from non-haematopoietic tissue was obtained from 6/16 NS-MPD patients, allowing the confirmation of a germline PTPN11 mutation.

The diagnosis of JMML or MPD was confirmed by a cytomorphological review of blood and bone marrow smears by a single expert (OF) and by the demonstration of endogenous myeloid progenitor cell growth in all patients who were tested (27 sporadic-JMML, 14 NS-JMML and 7 NS-MPD).

Because of the small number of patients and the continuum between the two haematological phenotypes, NS-JMML and NS-MPD patients were grouped together as a NS-MPD/JMML group for statistical analyses of phenotype/genotype correlations.

\section{Samples}

Peripheral blood and/or bone marrow aspirates were collected on EDTA at diagnosis. For patients with JMML or MPD, nonhaematopoietic tissues (fibroblasts, nails, amniotic fluid) were also collected. Genomic DNA was extracted using a Qiagen Mini or Midi Kit (Qiagen Gmbh, Hilden, Germany).

\section{Sequence analysis}

Mutation screening of PTPN11 was performed on genomic DNA by bi-directional Sanger sequencing of exons and their flanking intron-exon boundaries. ${ }^{19} 25$

\section{SNP array analysis}

SNP array analysis was performed using a GeneChip Human SNP Array 6.0 (Affymetrix, Santa Clara, California, USA) in paired leukocyte and fibroblast DNA samples. CEL files were created using Affymetrix GeneChip Command Console operating software and Genotyping Console 2.1, according to the manufacturer's protocols (Affymetrix). The Partek Genomics Suite

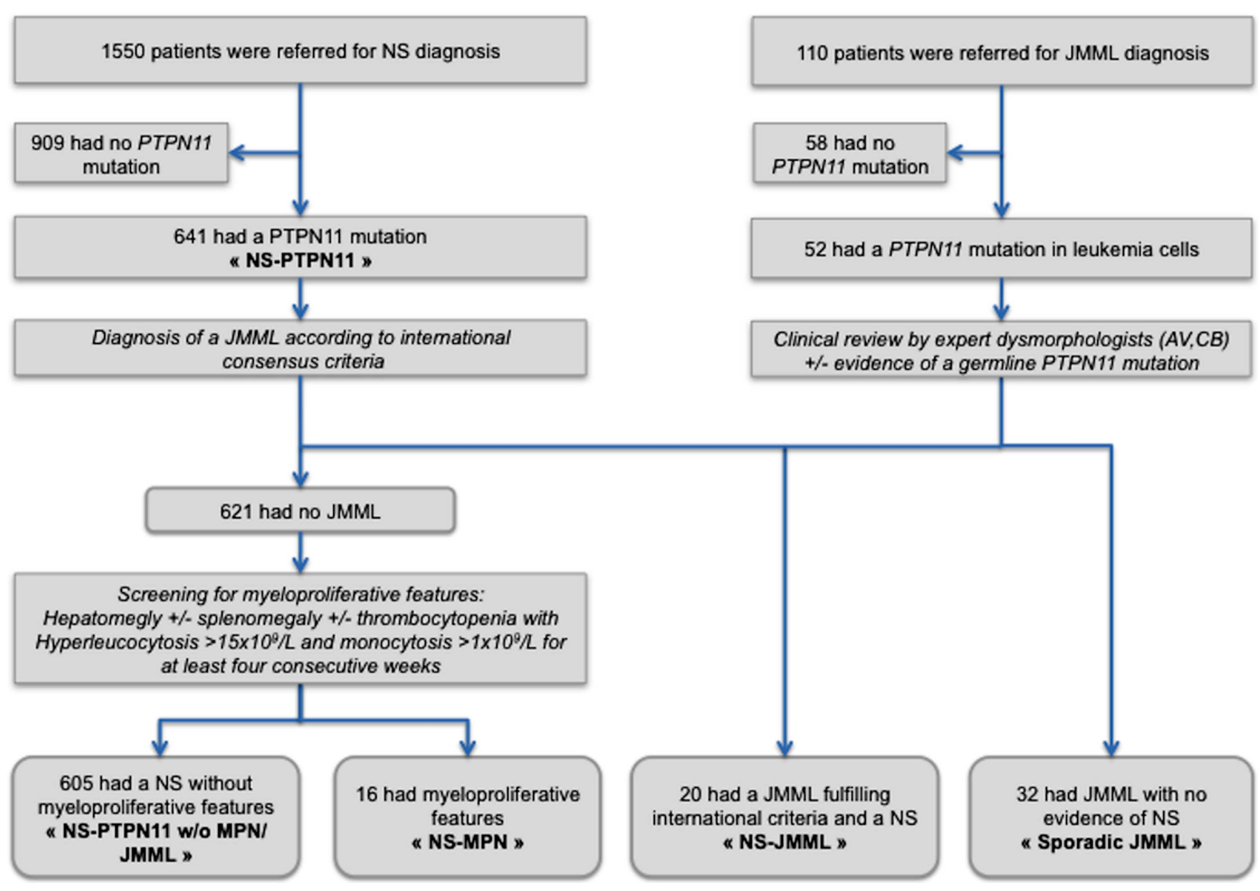

Figure 1 Flowchart and definition of the different groups of patients. 
was used for the analysis of both copy number alterations (CNA) and the loss of heterozygosity (LOH). Regions of $\mathrm{LOH}$ were detected using a Hidden Markov Model algorithm in the standard Partek workflow.

\section{Exome sequencing}

Targeted enrichment and massive parallel sequencing were performed on paired genomic DNA from leukocytes and fibroblasts. Exome capture was carried out using the SureSelect Human All Exon V4+UTRs (Agilent Technologies, Santa Clara, California, USA), and sequencing with a HiSeq2000 instrument (Illumina, San Diego, California, USA). Image analysis and base calling were performed using the Real Time Analysis (RTA) pipeline V. 1.14 (Illumina). The alignment of paired-end reads to the reference human genome (UCSC GRCh37/hg19) and variant calling were carried out using the CASAVA V.1.8 pipeline (Illumina). Variant annotation, SNP filtering (IntegraGen Exome databases, dbSNP135: (http://www.ncbi.nlm.nih.gov/projects/ SNP), 1000 Genomes: (http://www.1000genomes.org) and HapMap: (http://hapmap.ncbi.nlm.nih.gov)) and patientmatched germline variant filtering were achieved using an in-house pipeline by IntegraGen (Evry, France).

\section{Myeloid progenitor cell growth}

In vitro growth assays of myeloid progenitors were performed by plating bone marrow and/or peripheral blood mononucleated cells in semisolid methylcellulose with and without leukocyteconditioned medium (cytokine medium, LCM, StemCell Technologies, Vancouver, Canada). ${ }^{26}$ Colonies (aggregates containing $>50$ cells) were scored on days 11 and 14. 'Endogenous growth' corresponded to the presence of colony-forming units-granulo-monocyte (CFU-GM) $>10$ colonies or -monocyte $(\mathrm{CFU}-\mathrm{M})>5$ colonies) in the absence of growth factors.

\section{Clonality assay}

Clonality was assessed in female patients by analysing $\mathrm{X}$-chromosome inactivation patterns. The human androgen receptor gene (HUMARA) was assayed as previously described. ${ }^{27}$
Because a heterozygous pattern of methylation of the HUMARA locus has been reported in clonal haematopoietic cells, three additional loci (ZDHHC15, SLITRK4 and PCSK1N) were studied. $^{28} 29$ Briefly, methyl-specific digestion of DNA was performed separately by 2 endonucleases (HhaI, HpaII). The four loci were subsequently amplified by PCR. Reaction products were run on an automated capillary sequencer (ABI 3130 Genetic Analyzer, $\mathrm{ABI}$ ) using Genescan software (ABI). The ratio of inactive to active $\mathrm{X}$-chromosome was derived from the allelic ratio in digested and undigested DNA. ${ }^{30}$ DNA samples from 60 healthy age-matched patients and $2 \mathrm{X}$-skewed patients were used as negative and positive controls, respectively. The assay was considered informative when at least 3 markers showed heterozygosity. X-inactivation was considered to be skewed when the ratio was $>5$ for at least one locus.

\section{Statistical analysis}

Statistical analyses were performed using $\mathrm{R}$ software V.2.14.0 (http://www.R-project.org, the R Foundation for Statistical Computing, Vienna, Austria) and GraphPad Prism V.5.01 for Windows (GraphPad Software, San Diego California USA). Comparisons of quantitative variables and distributions were made using a non-parametric Kruskall-Wallis test, and Fisher's Exact, and $\chi^{2}$ tests, respectively.

\section{RESULTS}

\section{Myeloproliferation in NS}

We identified MPDs in 36/641 (5.6\%) NS patients with a germline PTPN11 mutation. Twenty patients $(3 \%)$ met the consensus diagnostic criteria for JMML (figure 1). Haematological anomalies most often appeared in the neonatal period, earlier than in patients with sporadic JMML (table 1). NS-MPD patients presented significantly milder clinical and biological anomalies than NS-JMML and sporadic JMML patients (table 1). Bone marrow aspiration of NS-JMML and sporadic-JMML patients showed similar cytological anomalies, that is, granular and/or erythroid hyperplasia. Monosomy 7 was not observed in any of the NS-JMML patients who were karyotyped $(n=15)$.

Table 1 Haematological features at diagnosis of NS-MPD, NS-JMML and sporadic PTPN11-JMML patients

\begin{tabular}{|c|c|c|c|c|}
\hline & NS-MPD ( $n=16)$ & NS-JMML $(n=20)$ & Sporadic JMML $(n=32)$ & p Value* \\
\hline Age at onset of haematological anomalies (months), median (IQ) & $1.1(0 ; 4)$ & $0.0(0.0 ; 0.1)$ & $32.5(18.5 ; 54.9)$ & $<0.01$ \\
\hline Splenomegaly, number of patients (\%) & $4(25)$ & $14(70)$ & $29(96.7)$ & $<0.01$ \\
\hline \multicolumn{5}{|l|}{ PBC counts median (IQ), $\times 109 / \mathrm{L}$} \\
\hline Platelets & $116.5(61.8-283)$ & $59(28.8-82.2)$ & $46(20-75)$ & $<0.01$ \\
\hline White blood cells & $21.9(15.7-24.2)$ & $39.1(28-57.9)$ & $32.2(18-47.6)$ & 0.02 \\
\hline Monocytes & $3.7(2.5-4.4)$ & $7(3.9-8.8)$ & $5(2.6-7.6)$ & ns \\
\hline Neutrophils & $5.8(4.1-8.2)$ & $19.4(7.2-31.1)$ & $9.8(6.8-14.6)$ & $<0.01$ \\
\hline Basophils & $0.1(0-0.2)$ & $0.2(0-0.5)$ & $0.4(0.2-0.6)$ & 0.02 \\
\hline Lymphocytes & $6.7(5.6-7.7)$ & $5.4(4.8-9.6)$ & $7.3(3.8-11.2)$ & ns \\
\hline Myeloid precursors in peripheral blood, number of patients (\%) & $10 / 13(76.9)$ & $19 / 20(95.0)$ & $25 / 26(96.2)$ & ns \\
\hline Circulating blasts, number of patients (\%) & $8 / 16(50.0)$ & $15 / 19(78.9)$ & $23 / 25(92.0)$ & $<0.01$ \\
\hline \multicolumn{5}{|l|}{ Bone marrow smear morphology } \\
\hline Granular hyperplasia & $2 / 3$ & $13 / 18$ & $14 / 26$ & \\
\hline Increased cellularity & $0 / 3$ & $3 / 18$ & $7 / 26$ & ns \\
\hline Erythroid hyperplasia & $0 / 3$ & $1 / 18$ & $5 / 26$ & \\
\hline Lymphoid hyperplasia & $1 / 3$ & $0 / 18$ & $0 / 26$ & \\
\hline Bone marrow myelodysplasia & $0 / 3$ & $6 / 18$ & $18 / 26$ & $<0.01$ \\
\hline
\end{tabular}


Six patients with NS-JMML had dysgranulopoiesis, of which two had an excess of undifferentiated blast cells (see online supplementary figure 1). Bone marrow aspiration performed in three NS-MPD patients showed granular hyperplasia in two and lymphoid hyperplasia in one patient. Clonality analysis in girls with NS-MPD $(n=6)$ or NS-JMML $(n=5)$ demonstrated skewed $\mathrm{X}$-inactivation suggestive of clonal haematopoiesis in $3 / 5$ informative girls with NS-MPD and in 2/4 informative girls with NS-JMML (see online supplementary figure 2).

\section{Clinical outcome}

None of the NS-MPD patients required chemotherapy, and all are alive, with a median follow-up time of 3.0 years (table 2; figure 2). The median time between diagnosis and the last

Table 2 Clinical presentation and follow-up of patients with NS-JMML and NS-MPD

\begin{tabular}{|c|c|c|c|c|c|c|c|c|c|c|}
\hline ID & $\begin{array}{l}\text { PTPN11 } \\
\text { mutation }\end{array}$ & Sex & $\begin{array}{l}\text { Age at onset of } \\
\text { haematological } \\
\text { signs, days }\end{array}$ & $\begin{array}{l}\text { Cardiac } \\
\text { failure }\end{array}$ & $\begin{array}{l}\text { Acute } \\
\text { respiratory } \\
\text { distress }\end{array}$ & $\begin{array}{l}\text { Initial treatment } \\
\text { (duration) }\end{array}$ & HSCT & $\begin{array}{l}\text { Age at last } \\
\text { follow-up, } \\
\text { years }\end{array}$ & $\begin{array}{l}\text { Status at last } \\
\text { follow-up* }\end{array}$ & Cause of death \\
\hline LMMJ-1 & p.Asp61His & M & 0 & - & + & 6-MP (2 days) & - & 0.1 (35 days) & Dead, PD & Respiratory failure \\
\hline LMMJ-2 & p.Asn308Ser & $M$ & 0 & - & + & No & - & 0 (15 days) & Dead, PD & Respiratory failure \\
\hline LMMJ-3 & p.Asp61His & $\mathrm{M}$ & 0 & + & + & $\begin{array}{l}\text { 6-MP (1 month), } \\
\text { ETO, ARAC }\end{array}$ & - & 0.3 & Dead, PD & Respiratory failure \\
\hline LMMJ-4‡ & p.Asp61Gly & M & 0 & - & - & No & - & 0 (14 days) & Dead, PD & Brain haemorrhage \\
\hline LMMJ-5 & p.Gly60Ala & $M$ & 0 & + & + & No & - & 0 (9 days) & Dead, PD & $\begin{array}{l}\text { Respiratory and } \\
\text { cardiac failure }\end{array}$ \\
\hline LMMJ-6 & p.GIn506Pro & M & 0 & + & - & No & - & 0.1 (41 days) & Dead, SD & $\begin{array}{l}\text { Cardiac failure after } \\
\text { cardiac surgery }\end{array}$ \\
\hline LMMJ-7 & p.Phe71Leu & $\mathrm{F}$ & 0 & + & - & No & - & 0.1 (35 days) & Dead, SD & $\begin{array}{l}\text { Cardiac failure after } \\
\text { cardiac surgery }\end{array}$ \\
\hline LMMJ-8 & p.Ala72Gly & M & 0 & - & + & No & - & 0 (14 days) & Dead, PD & Respiratory failure \\
\hline LMMJ-9 & p.Glu139Asp & $\mathrm{M}$ & 4 & + & + & No & - & 0 (18 days) & Dead, PD & Cardiac failure \\
\hline LMMJ-10 & p.Phe285Leu & $\mathrm{M}$ & 0 & + & + & No & - & 0.2 (61 days) & Dead, PD & \\
\hline LMMJ-11 & p.Asn308Asp & M & 0 & - & + & 6-MP (1 year) & + & 6.2 & Alive, CR & NA \\
\hline LMMJ-12 & p.Thr73Ile & $M$ & 0 & - & + & 6-MP (1 month) & - & 3.0 & $\begin{array}{l}\text { Alive, CR with } \\
\text { amegakaryocytosis }\end{array}$ & NA \\
\hline LMMJ-13 & p.Gly503Arg & $\mathrm{F}$ & 0 & - & - & No & - & 8.8 & Alive, CR & NA \\
\hline LMMJ-14 & p.Asp61Gly & $\mathrm{F}$ & 56 & - & - & 6-MP (2 years) & - & 2.2 & Alive, CR & NA \\
\hline LMMJ-15 & p.Thr73lle & $\mathrm{M}$ & 55 & - & - & No & - & 3.4 & Alive, CR & NA \\
\hline LMMJ-16 & p.Ala72Gly & $\mathrm{M}$ & 3 & - & - & No & - & 3.1 & Alive, PR & NA \\
\hline LMMJ-17 & p.Thr73lle & $\mathrm{F}$ & 0 & - & - & 6-MP (1 year) & - & 1.6 & $\begin{array}{l}\text { Alive, CR, } \\
\text { Neuroblastoma } \\
\text { at } 1 \text { year }\end{array}$ & NA \\
\hline LMMJ-18§ & p.Asp61Asn & $\mathrm{M}$ & 70 & - & - & No & - & 3.2 & $\begin{array}{l}\text { Dead, undetermined } \\
\text { disease status }\end{array}$ & $\begin{array}{l}\text { Respiratory failure } \\
\text { of unknown origin }\end{array}$ \\
\hline LMMJ-19 & p.Gly503Arg & M & 56 & - & - & 6-MP (1 year) & + & 1.3 & Dead, CR & $\begin{array}{l}\text { Post allograft } \\
\text { infections }\end{array}$ \\
\hline LMMJ-20 & p.Phe285Leu & $\mathrm{F}$ & 0 & - & - & No & - & 0.6 & Dead, SD & $\begin{array}{l}\text { Cardiac failure after } \\
\text { cardiac surgery }\end{array}$ \\
\hline MPD-1 & p.Thr42Ala & M & 14 & - & - & No & - & 3.9 & Alive & NA \\
\hline MPD-2 & p.Asp61Asn & $\mathrm{M}$ & 670 & - & - & No & - & 5.6 & Alive & NA \\
\hline MPD-3 & p.Asp61Gly & $\mathrm{F}$ & 0 & + & + & $\begin{array}{l}\text { Corticosteroids, } \\
\text { IVIG, EPO }\end{array}$ & - & 3.2 & Alive & NA \\
\hline MPD-4 & p.Asp61Asn & $\mathrm{F}$ & 0 & - & + & No & - & 2.0 & Alive & NA \\
\hline MPD-5 & p.Glu139Asp & $M$ & 0 & - & - & No & - & 4.8 & Alive & NA \\
\hline MPD-6 & p.Asn308Ser & $\mathrm{F}$ & 217 & - & - & No & - & 3.7 & Alive & NA \\
\hline MPD-7 & p.Asp61Asn & $\mathrm{F}$ & 44 & - & - & No & - & 8.4 & Alive & NA \\
\hline MPD-8 & p.Asn308Ser & M & 0 & - & - & No & - & 1.4 & Alive & NA \\
\hline MPD-9 & p.Asn308Ser & M & 0 & - & - & No & - & 1.1 & Alive & NA \\
\hline MPD-10 & p.Glu139Asp & M & 234 & - & - & No & - & 4.8 & Alive & NA \\
\hline MPD-11 & p.Thr42Ala & M & 0 & - & - & IVIG & - & 4.0 & Alive & NA \\
\hline MPD-12 & p.Asp61Gly & $\mathrm{F}$ & 51 & - & - & No & - & 1.6 & Alive & NA \\
\hline MPD-13 & p.Asn308Asp & $\mathrm{F}$ & 21 & - & - & No & - & 0.8 & Alive, ALL at 2 years & NA \\
\hline MPD-14 & p.Tyr62Asp & M & 207 & - & - & No & - & 3.1 & Alive & NA \\
\hline MPD-15 & p.Ser502Leu & $M$ & 50 & - & - & No & - & 0.7 & Alive & NA \\
\hline MPD-16 & p.Thr73lle & $\mathrm{F}$ & 90 & - & - & No & - & 0.6 & Alive & NA \\
\hline
\end{tabular}

${ }^{*}$ Response to treatment was considered complete (CR) if WBC count was $<20 \times 10^{9} / \mathrm{L}$ and spleen size was normalised. A partial response (PR) corresponded to a WBC count $<50 \%$ of initial count but still greater than $20 \times 10^{9} / \mathrm{L}$ and a $25 \%$ decrease in spleen size.

tPreviously reported in Giovannini et al. ${ }^{31}$

$\S$ No germline DNA available for this patient.

6-MP, 6-mercaptopurine; ALL, acute lymphoblastic leukaemia; ARAC, Aracytine; EPO, erythropoietin; ETO, Etoposide; F, female; HSCT, haematopoietic stem cell transplantation;

IVIG, intravenous immunoglobulin; M, male; NA, not applicable; PD, progressive disease; SD, stable disease. 
peripheral blood cell count was 38.8 months (min-max; 14.1143.8). At this time point, monocytosis and/or thrombocytopenia persisted in $8 / 16$ patients. Notably, patient \#13 developed a hyperdiploid B-cell progenitor acute lymphoblastic leukaemia (BCP-ALL) at the age of two years.

Life-threatening complications related to congenital heart defects, pleural effusion, leukaemia infiltrates and/or thrombocytopenia were noted in $12 / 20(60 \%)$ NS-JMML patients (table 2). Ten of these 12 patients died soon after diagnosis (median time ([min-max): 26.5 days (9-124)) from haemodynamic failure, respiratory failure or cerebral haemorrhage. Anti-tumoral chemotherapy (6-mercaptopurine, cytarabine and etoposide) was administered in two patients (\#1 and \#3). After a transient clinical improvement, both died in a context of rapid WBC rise or blast crisis. The other patients received only supportive care. Necropsies of patients \#1, \#8 and \#10, who died of pulmonary failure, revealed major tumoral infiltration of the lungs, confirming the causal link between JMML and death. In patients \#2, \#3 and \#5, pulmonary and cardiac failure were strongly suspected to have been increased by visceral tumoral infiltration, since the WBC count rose rapidly and reached its highest level on the day of death. For patient \#4, a cerebral haemorrhage was diagnosed at 3 days of life in a context of thrombocytopenia $\left(28 \times 10^{9} / \mathrm{L}\right)$ related to JMML. Patient \#12 had an unusual evolution. He achieved complete remission (CR) of JMML according to standard criteria, but had persistent severe thrombocytopenia 1 year after CR. Repeated bone marrow smears confirmed amegakaryocytosis.

In the remaining eight patients with NS-JMML, haematological symptoms appeared between birth and 7 months, and were related to tumoral infiltrates in the viscera. None of these patients required intensive care at diagnosis or during follow-up. Three were treated with 6-mercaptopurine and reached CR (patients \#14, \#17 and \#19). Patient \#17 subsequently developed a neuroblastoma. Five patients who did not receive any chemotherapy had either a complete (\#13 and \#15) or partial (\#16, \#18 and \#20) spontaneous remission. Three of them (\#18, \#19 and \#20) died later, under circumstances not directly related to their initial haematological presentation, from either pulmonary infection, postallograft toxicity, or cardiac surgery complications.

With a median follow-up time of 2.8 years, the 2 -year overall survival rate was, respectively, 40.0\% ( $\mathrm{SE}=11.0 \%), 100 \%$ and $61.8 \%(\mathrm{SE}=9.6 \%)$ for NS-JMML, NS-MPD, and sporadic JMML (figure 2). Only 2/20 patients with NS-JMML received haematopoietic stem cell transplantation, versus 23/32 patients with sporadic JMML.

Interestingly, compared to the rest of the NS-PTPN11 cohort $(n=605)$, NS-JMML and NS-MPD patients showed a higher rate of polyhydramnios (table 3). There was no difference based on gestational age or growth retardation; NS patients who developed MPD/JMML tended to have a more severe neonatal presentation with a higher frequency of hemodynamic and/or respiratory failure related to chylothorax and heart defects (table 3). Surprisingly, 11/12 (91.6\%) patients with severe neonatal manifestations were males, which is significantly different from the sex-ratio in NS-PTPN11 patients $(p=0.03)$

\section{Pattern of PTPN11 mutations}

We compared the pattern of PTPN11 mutations in 3 groups: (1) sporadic JMML patients; (2) NS-JMML/MPD patients and (3) NS-PTPN11 patients with no MPD (table 4). For 30/32 patients (93.7\%), acquired somatic mutations were clustered in codons Asp61, Ala72 and Glu76. None of the substitutions identified in

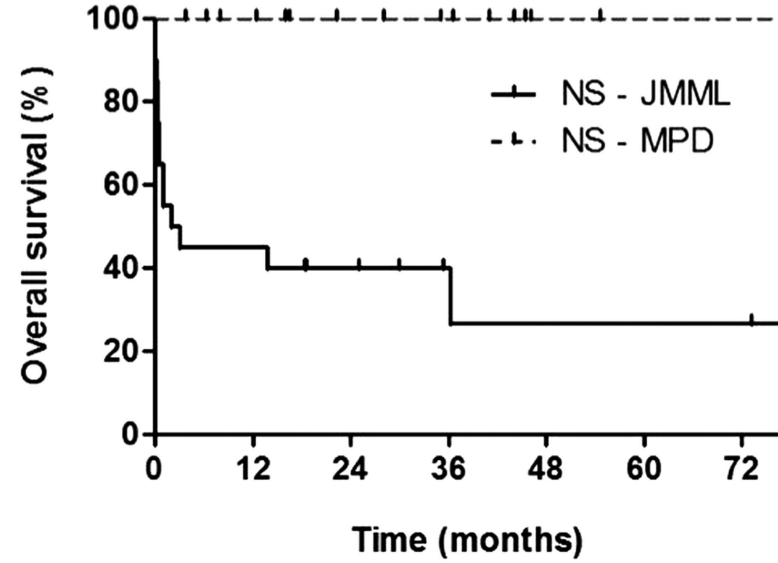

$\mathrm{Nb}$. at risk

$\begin{array}{llllllll}\text { NS - JMML } & 20 & 10 & 7 & 4 & 3 & 3 & 2\end{array}$

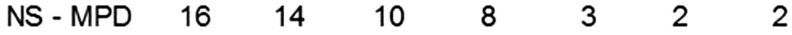

Figure 2 Kaplan-Meier curves of survival in patients with NS-MPD and NS-JMML.

sporadic JMML was found in patients with NS. Mutations identified in NS-JMML/MPD patients overlapped with those of common NS patients, but some of them were over-represented. Among 5 NS patients with a p.Thr73Ile mutation, 3 had JMML and 1 had MPD. These 4 patients suffered a mild clinical course with the spontaneous improvement of haematological anomalies. The most frequent mutations, targeting codon Asp61, were also over-represented: 10/36 (28\%) in NS-MPD/JMML versus $38 / 605(6 \%)$ in NS patients $(\mathrm{p}<0.01)$. Among patients with these mutations, $10 / 48$ \{20.8\%-5\% CI 10.5 to $35.0 \%\}$ developed MPD in early childhood (table 4). Strikingly, a p. Asp61His, reported once in AML, ${ }^{32}$ but never seen previously in NS, was found in two NS-JMML patients (\#1, \#3). These male patients suffered from a particularly aggressive form of neonatal JMML that rapidly led to death, after a blast crisis in one patient (table 2; online supplementary figure 1).

Almost all PTPN11 mutations found in sporadic JMML cases affect the switch properties of the encoded enzyme, SHP2. ${ }^{21}$ Some mutations found in NS-JMML/MPD affect SHP2 catalysis or specificity (see online supplementary table 1). According to the classification proposed by Tartaglia and others, ${ }^{17}$ an excess of class I mutations is observed in NS-JMML/MPD patients, with a rate between that of sporadic JMML and NS.

Taken together, these data suggest that some germline PTPN11 mutations are more likely to induce myeloproliferation in infants. However, most PTPN11 mutations identified in NS-MPD/JMML patients were also found in NS patients with no haematological phenotype. For instance, only 2/133 (1.5\%) patients with p.Asn308Asp had haematological anomalies. Moreover, in 4 patients (NS-JMML: \#18, \#2, \#5 and NS-MPD: \#5), the mutation was inherited from a parent with no history of MPD.

\section{Pangenomic screening for a second hit}

We thus investigated whether somatic genetic lesions could participate in the occurrence of JMML in NS patients. Twelve paired germline/leukaemia samples were analysed by SNP array and eight of these were further subjected to whole exome sequencing. We identified a subclonal duplication of the $\mathrm{X}$-chromosome in one male patient. Another male patient with NS-JMML had a mosaic Klinefelter syndrome (patient \#8: 47, 
Table 3 Perinatal features of NS patients according to the presence of haematological manifestations

\begin{tabular}{|c|c|c|c|c|}
\hline & NS-PTPN11 without MPD/JMML $(\mathrm{n}=605)$ & NS-MPD ( $n=16)$ & NS-JMML $(n=20)$ & p Value* \\
\hline Sex ratio & 1.3 & 1.3 & 3 & ns \\
\hline Antenatal hydramnios (\%) & $71(11.7)$ & $4 / 13(30.8)$ & $10 / 20(50)$ & $<0.01$ \\
\hline Intra-uterine growth retardation in SD, median (IQ) $\dagger$ & $-0.6(-1.5 ; 0.2)$ & $-1(-1 ; 0)$ & $-0.5(-1 ; 0)$ & ns \\
\hline Cardiomyopathy $\ddagger(\%)$ & $109(18)$ & $2(12.5)$ & $6(30)$ & ns \\
\hline Congenital heart disease $(\%)$ & $296(49)$ & $8(50)$ & $15(75)$ & ns \\
\hline Neonatal acute cardiac failure§ (\%) & $<1 \%$ & $1 / 16(6.2)$ & $6 / 20(30.0)$ & $<0.01$ \\
\hline Neonatal acute respiratory failure ${ }^{\pi}(\%)$ & $<1 \%$ & $3 / 16(18.7)$ & $8 / 20(40.0)$ & $<0.01$ \\
\hline Death before the age of five years (\%) & $6(0.99)^{* *}$ & $0 / 16(0)$ & $13 / 20(65.0)$ & $<0.01$ \\
\hline
\end{tabular}

XXY (13)/46, XY (7)). However, no compound heterozygosity or co-occurrence of a second germline mutation targeting genes known to be involved in RASopathies (NRAS, KRAS, HRAS, PTPN11, SOS1, BRAF, RAF1, CBL, SHOC2, SPRED1, NF1, RIT1) were identified in these eight NS-JMML cases.

\section{DISCUSSION}

Children with NS are predisposed to a spectrum of haematologic abnormalities including MPDs, which may regress without treatment or follow a more aggressive clinical course resembling JMML. $^{2}{ }^{4}{ }^{13}$ Little is known about the natural history of the disease and potential phenotype/genotype correlations. Several cases of NS-JMML have been reported individually, but the incidence of MPDs in NS has not been estimated. Kratz et al reported eight new NS-JMML/MPD patients and reviewed 11 cases from the literature, while Timeus $e t a l^{33}$ reported three patients. $^{14}$

We identified haematological features typically associated with myeloproliferation in $36 / 641$ (5.6\%) NS patients with a germline PTPN11 mutation. Twenty of them met the consensus diagnostic criteria for JMML and 16 had MPD. The strength of our study comes from the central position of our lab in the molecular diagnosis of both NS and JMML in France, which reduces the likelihood that only severe or haematological cases were examined. However, considering the weaknesses inherent in our a posteriori, declarative mode of ascertainment of MPD cases, and the absence of systematic haematological screening in NS patients, this incidence may be an underestimate.

The haematological features observed in our patients encompassed a broad phenotypic spectrum ranging from transient MPD to clinical courses similar to sporadic PTPN11-JMML. According to clinical and haematological data, patients were found clustered in two groups. The first group accounted for about $2 \%$ of NS cases and followed a mild clinical course. Some of these patients were transiently treated to control myeloproliferation but all underwent spontaneous remission. Most patients reported so far in the literature belong to this group, suggesting that NS patients do not develop severe JMML. ${ }^{14}$ However, our study identified a second group of patients who represented 3\% of NS cases. These patients developed bona fide JMML, often with an excess of blasts and very severe neonatal manifestations. Half of them died in the first month of life. Few patients have been reported in the literature with similar features. ${ }^{21-23} \mathrm{We}$ thus suspect that JMML may have been overlooked due to the early death of such infants in neonatal intensive care units, the presence of comorbidities and the lack of specific confirmatory tests. Intriguingly, the majority of patients with severe neonatal JMML were males.

NS-PTPN11 has a low infantile mortality even if some cases remain undiagnosed: fetuses terminated for incurable heart defects, or spontaneous fetal death due to hydrops. By contrast, the survival of NS-JMML patients is very poor (table 2). In our series of NS-PTPN11, JMML is the first cause of death in childhood. Whether cardiac or respiratory failure leading to death is a consequence of myeloproliferation and tumoral infiltrates in the lung, or whether mutations that induce myeloproliferation also induce a more severe general disorder remains an open but important question. The latter assumption may discourage aggressive leukaemia therapy in children whose prognosis is likely to remain poor.

It would thus be important to distinguish patients who will spontaneously recover from those who will have a more severe disease course. The endogenous growth of myeloid progenitors, a hallmark of JMML related to the selective hypersensitivity of these cells to GM-CSF, has been found in all patients who were tested, and cannot be used to predict the severity of haematopoietic complications. No difference in clonal patterns could be seen between patients with NS-JMML and NS-MPD, but the clonality assay suffers from limitations and must be interpreted with caution. An excess of blasts or blast crisis was shown in two male patients who experienced a severe clinical course, in line with previous observations. ${ }^{4} 11$ These observations strongly support the malignant nature of myeloproliferation in some patients.

The development of MPD and JMML in NS show striking similarities with other pretumoral syndromes in infants, such as transient acute myeloproliferation in Down syndrome, that can either spontaneously regress or evolve towards malignancy. ${ }^{34}$ However, while GATA-1 mutations mark myeloproliferation in Down syndrome, our exome and array studies did not identify any cooperative somatic mutation that could drive leukaemogenesis. Additionaly, no second germline genetic variation in NS genes was associated with the occurrence of JMML in NS patients, as previously described in patients with NS who underwent fetal death or early malignancy. 3536

PTPN11 mutations associated with NS-JMML/MPD were clustered in a limited number of amino acids. In line with previous reports, ${ }^{14} 1837$ p.Thr73Ile mutation was strongly associated with haematological disorders. However, it was present in only 4/36 (11.1\%) of NS-JMML/MPD patients of our cohort, 
Table 4 PTPN11 (NM_002834) mutations identified in sporadic JMML ( $\mathrm{n}=32$ ) and NS-JMML/MPD ( $\mathrm{n}=36$ ) in comparison with the prevalence of these mutations in NS patients who did not develop myeloproliferative disease $(n=605)$

\begin{tabular}{|c|c|c|c|c|c|c|c|c|}
\hline Mutation & Exon & Domain & $\begin{array}{l}\text { Mutation } \\
\text { group (17) }\end{array}$ & $\begin{array}{l}\text { Sporadic JMML } \\
\text { PTPN11 }^{\text {mut }}(\mathrm{n}=32)\end{array}$ & $\begin{array}{l}\text { NS-JMML/MPD } \\
(n=36)\end{array}$ & $\begin{array}{l}\text { NS-JMML/MPD } \\
(14)(n=8)\end{array}$ & $\begin{array}{l}\text { NS-JMML/MPD } \\
(30)(n=3)\end{array}$ & $\begin{array}{l}\text { NS-PTPN11 without } \\
\text { MPD/JMML }(n=605)\end{array}$ \\
\hline p.Thr42Ala & 2 & $\mathrm{~N}-\mathrm{SH} 2$ & V & - & $2(5.5 \%)$ & - & - & $5(0.8 \%)$ \\
\hline p.Gly60Ala & 3 & $\mathrm{~N}-\mathrm{SH} 2$ & I & - & $1(2.8 \%)^{*}$ & - & - & $10(1.6 \%)$ \\
\hline p.Gly60Arg & 3 & $\mathrm{~N}-\mathrm{SH} 2$ & I & $2(6.2 \%)$ & - & - & - & \\
\hline p.Asp61Gly & 3 & $\mathrm{~N}-\mathrm{SH} 2$ & 1 & - & $4(11.1 \%)$ & 2 & - & $18(3.0 \%)$ \\
\hline p.Asp61His & 3 & $\mathrm{~N}-\mathrm{SH} 2$ & 1 & - & $2(5.5 \%) \ddagger$ & - & - & $0(0 \%)$ \\
\hline p.Asp61Asn & 3 & $\mathrm{~N}-\mathrm{SH} 2$ & I & - & $4(11.1 \%)^{*}$ & - & 2 & $20(3.3 \%)$ \\
\hline p.Asp61Val & 3 & $\mathrm{~N}-\mathrm{SH} 2$ & I & $6(18.7 \%)$ & - & - & - & - \\
\hline p.Asp61Tyr & 3 & $\mathrm{~N}-\mathrm{SH} 2$ & I & $4(12.5 \%)$ & - & - & - & - \\
\hline p.Tyr62Asp & 3 & $\mathrm{~N}-\mathrm{SH} 2$ & I & - & $1(2.8 \%)$ & - & - & $15(2.5 \%)$ \\
\hline p.Phe71Leu & 3 & $\mathrm{~N}-\mathrm{SH} 2$ & I & - & $1(2.8 \%)$ & - & - & $0(0 \%)$ \\
\hline p.Ala72Thr & 3 & $\mathrm{~N}-\mathrm{SH} 2$ & 1 & $2(6.2 \%)$ & - & - & - & - \\
\hline p.Ala72Val & 3 & $\mathrm{~N}-\mathrm{SH} 2$ & I & $4(12.5 \%)$ & - & - & - & - \\
\hline p.Ala72Gly & 3 & $\mathrm{~N}-\mathrm{SH} 2$ & I & - & $2(5.5 \%)$ & 1 & - & $6(1.0 \%)$ \\
\hline p.Thr73Ile & 3 & $\mathrm{~N}-\mathrm{SH} 2$ & I & - & $4(11.1 \%)$ & 2 & - & $1(0.2 \%)$ \\
\hline p.Glu76Gly & 3 & $\mathrm{~N}-\mathrm{SH} 2$ & I & $6(18.7 \%)$ & - & - & - & - \\
\hline p.Glu76Ala & 3 & $\mathrm{~N}-\mathrm{SH} 2$ & I & $1(3.1 \%)$ & - & - & - & - \\
\hline p.Glu76Lys & 3 & $\mathrm{~N}-\mathrm{SH} 2$ & I & $3(9.4 \%)$ & - & - & - & - \\
\hline p.Glu76Gln & 3 & $\mathrm{~N}-\mathrm{SH} 2$ & I & $1(3.1 \%)$ & - & - & - & - \\
\hline p.Glu76Val & 3 & $\mathrm{~N}-\mathrm{SH} 2$ & 1 & $1(3.1 \%)$ & - & - & - & - \\
\hline p.Glu139Asp & 4 & linker & V & - & $3(8.3 \%)^{*}+$ & - & - & $30(5.0 \%)$ \\
\hline p.Phe285Ser & 7 & PTP & IV & - & $1(2.8 \%)$ & & & $8(1.3 \%)$ \\
\hline p.Phe285Leu & 7 & PTP & IV & - & $1(2.8 \%)$ & - & 1 & $0(0 \%)$ \\
\hline p.Asn308Ser & 8 & PTP & IV & - & $4(11.1 \%)^{*}$ & - & - & $22(4.1 \%)$ \\
\hline p.Asn308Asp & 8 & PTP & IV & - & $2(5.5 \%)$ & - & - & $131(21.7 \%)$ \\
\hline p.Arg498Trp & 13 & PTP & IV & - & - & 1 & - & $4(0.6 \%)$ \\
\hline p.Ser502Leu & 13 & PTP & III & - & $1(2.8 \%)$ & & & $0(0 \%)$ \\
\hline p.Ser502Ala & 13 & PTP & III & - & - & 1 & - & $5(0.8 \%)$ \\
\hline p.Gly503Ala & 13 & PTP & III & $2(6.2 \%)$ & - & - & - & $0(0 \%)$ \\
\hline p.Gly503Arg & 13 & PTP & III & - & $2(5.5 \%)$ & - & - & $19(3.1 \%)$ \\
\hline p.GIn506Pro & 13 & PTP & $\|$ & - & $1(2.8 \%)$ & 1 & - & $4(0.7 \%)$ \\
\hline
\end{tabular}

whereas, it has previously been reported by Kratz et $a l^{14}$ to be the most common mutation in JMML/MPD (42\%). However, these authors did not report patients with severe neonatal JMML leading to early death, suggesting that their patient ascertainment method was different and overlooked neonatal cases. This over-representation of the p.Thr73Ile mutation in previous studies could explain why patients with NS are often considered to develop mild MPD with spontaneous regression rather than bona fide JMML. Indeed, in our series, the clinical presentation varied from a mild course with spontaneous recovery for all $\mathrm{p}$. Thr73Ile patients to rapidly fatal neonatal disease in patients with p.Asp61His. Mutant SHP2 proteins associated with malignancies are more activating than those observed in NS. ${ }^{20} 21$ This supports a model in which a higher gain-of-function threshold for SHP2 activity is required to induce leukaemia: the relatively mild gain-of-function effects of the SHP2 mutants associated with NS are usually inadequate to deregulate haematopoietic precursor cell proliferation, whereas, PTPN11 mutations found in isolated malignancies have higher gain-of-function effects incompatible with embryonic development. We confirmed this general observation in our patients: Asp61His, the only mutation observed in somatic leukemias and NS, caused a severe phenotype leading to the death of both patients soon after birth.

In line with murine models, our observations support the view of a strong endogenous role of a germline PTPN11 mutation in the occurrence of myeloproliferative complications, ${ }^{38}$ and the existence of high-risk mutations. Nevertheless, the risk of developing MPD or JMML cannot be precisely predicted by the underlying PTPN11 mutation, since only a fraction of patients with a given mutation will develop a haematological disease, even within a family.

In conclusion, NS may be associated with early onset, lifethreatening haematological complications. RASopathies and MPDs are probably overlooked in cases of early lethality or in patients hospitalised in neonatal or paediatric intensive care units, and surely overlooked after a termination of pregnancy. Haematological evaluation should be performed systematically in newborns with severe haemodynamic or respiratory failure clinically suspected of having NS, without delaying these investigations until the presence of a mutation is confirmed. Our observations confirm that infants with NS-MPD should be managed conservatively unless refractory cytopenias, compromised vital organ functions, or an overt leukaemia with blast 
crisis develops. ${ }^{34}$ In particular, excessive hyperleucocytosis may be observed in certain clinical stressful situations, that is, during infections or after surgery, in NS-MPD patients, with no clinical symptoms and spontaneous decrease.

We recommend that all NS children be systematically evaluated for clinical signs of MPD (splenomegaly, hepatomegaly) and basic haematological parameters at least every 3 months during the first year of life, and twice during the second year of life. Of particular concern is the observation that two of the 22 NS children who survived MPD/JMML developed a second tumour later in childhood, suggesting that these children deserve a very close clinical follow-up.

\section{Author affiliations}

${ }^{1}$ INSERM UMR_S1131, Institut Universitaire d'Hématologie, Université Paris Diderot, Paris-Sorbonne-Cité, Paris, France

2Département de Génétique, Assistance Publique des Hôpitaux de Paris (AP-HP), Hôpital Robert Debré, Paris, France

${ }^{3}$ Service de Biologie Cellulaire, Assistance Publique des Hôpitaux de Paris (AP-HP), Hôpital Saint Louis, Paris, France

${ }^{4}$ INSERM UMR_1137, IAME, Plateforme de Génétique constitutionnelle-Nord (PfGCNord), Université Paris Diderot, Paris, France

${ }^{5}$ Service d'Hématologie Biologique, Assistance Publique des Hôpitaux de Paris (APHP), Hôpital Robert Debré, Paris, France

${ }^{6}$ Service d'Onco-Hématologie pédiatrique, Hôpital d'Enfants de Brabois, Vandoeuvre lès Nancy, France

${ }^{7}$ Service d'Onco-Hématologie pédiatrique, $\mathrm{CHU}$ de Nice, Nice, France

${ }^{8}$ Service d'Onco-Hématologie pédiatrique, CHU de Nantes, Nantes, France

${ }^{9}$ Réanimation néonatale pédiatrique, Paris Assistance Publique des Hôpitaux de Paris (AP-HP), Hôpital Trousseau, Paris, France

${ }^{10}$ Service d'Onco-Hématologie pédiatrique, CHU de Grenoble, Grenoble, France

${ }^{11}$ Service de Pédiatrie, Hôpital de Hautepierre, Strasbourg, France

${ }^{12}$ Unité d'Epidémiolgie Clinique, Assistance Publique des Hôpitaux de Paris (AP-HP) Hôpital Robert Debré, Paris, France

${ }^{13}$ INSERM, U1123 et CIC-EC 1426, ECEVE, Université Paris Diderot, Paris-SorbonneCité, Paris, France

${ }^{14}$ Institute of Human Genetics, University Hospital Magdeburg, Magdeburg, Germany

${ }^{15}$ Département d'Immunologie et Hématologie Pédiatrique, Institut d'HématoOncologie Pédiatrique (IHOP), Lyon, France

${ }^{16}$ Service d'Hématologie pédiatrique, Assistance Publique des Hôpitaux de Paris APHP, Hôpital Robert Debré, Paris, France

${ }^{17}$ INSERM UMR S1141, Hôpital Robert Debré, Université Paris Diderot, ParisSorbonne-Cité, Paris, France

Acknowledgements SNP-array analyses were performed in the 'Plateforme de Génomique constitutionnelle-Nord' (PfGC-Nord) (J Soulier, S Quentin). We thank Jocelyne Vivent for help with clinical data collection. We also acknowledge the network of haematologists, neonatologists, geneticists, cytologists and pathologists who participated in the diagnosis and care of the children: Drs B Isidor, A David and S Denizot (Nantes), J Tandonnet, S Ducassou, M Micheau and N Aladjidi (Bordeaux), G Plat and S Julia (Toulouse), M Poirée and F Guiliano (Nice), F Cartault (St Denis-la Réunion), C Pondarre, MP Pages, and F Alsohim (Lyon), P Brosset (Limoges), E Kermorvant (Paris-Necker), L Jules and V Picard (Paris-Bicêtre), A Petit, A Coulomb and H Lapillonne (Paris-Trousseau), C Samson (Nouméa), B Leheup (Nancy), R Touraine (St Etienne), F Petit, M Holder-Espinasse and B Nelken (Lille), J Roume (St Germain-en-Laye) and B Doray, Patrick Lutz (Strasbourg).

Contributors MS, AC, BC, SP and JL performed experiments and data analysis. SG and $C A$ made the statistical analysis. OF performed cytomorphological review of blood and bone marrow smears. NP performed data management. $C B, A C, N S, F M$, $I G, D A, C P, Y B$ and $A B$ were involved in local study implementation, patient recruitement and reviewed the manuscript. MS, AV, MZ, CC and $\mathrm{HC}$ wrote the manuscript. $\mathrm{HC}$ designed and supervised the study and the writing of the manuscript.

Competing interests None.

Ethics approval INSERM.

Provenance and peer review Not commissioned; externally peer reviewed.

\section{REFERENCES}

1 Roberts AE, Allanson JE, Tartaglia M, Gelb BD. Noonan syndrome. Lancet 2013:381:333-42.

2 Hasle H. Malignant diseases in Noonan syndrome and related disorders. Horm Res 2009:72(Suppl 2):8-14.
3 Kratz CP, Rapisuwon S, Reed H, Hasle H, Rosenberg PS. Cancer in Noonan, Costello, cardiofaciocutaneous and LEOPARD syndromes. Am J Med Genet C Semin Med Genet 2011:157C:83-9.

4 Bader-Meunier B, Tchernia G, Miélot F, Fontaine JL, Thomas C, Lyonnet S, Lavergne JM, Dommergues JP. Occurrence of myeloproliferative disorder in patients with Noonan syndrome. J Pediatr 1997;130:885-9.

5 Tefferi A, Vainchenker W. Myeloproliferative neoplasms: molecular pathophysiology, essential clinical understanding, and treatment strategies. I Clin Oncol Off J Am Soc Clin Oncol 2011;29:573-82.

6 Niemeyer CM, Arico M, Basso G, Biondi A, Cantu Rajnoldi A, Creutzig U, Haas O, Harbott J, Hasle H, Kerndrup G, Locatelli F, Mann G, Stollmann-Gibbels B, van't Veer-Korthof ET, van Wering E, Zimmermann M. Chronic myelomonocytic leukemia in childhood: a retrospective analysis of 110 cases. European Working Group on Myelodysplastic Syndromes in Childhood (EWOG-MDS). Blood 1997;89:3534-43.

7 Loh ML. Recent advances in the pathogenesis and treatment of juvenile myelomonocytic leukaemia. Br J Haematol 2011;152:677-87.

8 Chan RJ, Cooper T, Kratz CP, Weiss B, Loh ML. Juvenile myelomonocytic leukemia: a report from the 2nd International JMML Symposium. Leuk Res 2009;33:355-62.

9 Emanuel PD, Bates LJ, Castleberry RP, Gualtieri RJ, Zuckerman KS. Selective hypersensitivity to granulocyte-macrophage colony-stimulating factor by juvenile chronic myeloid leukemia hematopoietic progenitors. Blood 1991;77:925-9.

10 Fukuda M, Horibe K, Miyajima Y, Matsumoto K, Nagashima M. Spontaneous remission of juvenile chronic myelomonocytic leukemia in an infant with Noonan syndrome. J Pediatr Hematol Oncol 1997;19:177-9.

11 Choong K, Freedman MH, Chitayat D, Kelly EN, Taylor G, Zipursky A. Juvenile myelomonocytic leukemia and Noonan syndrome. J Pediatr Hematol Oncol 1999:21:523-7.

12 Yoshida R, Miyata M, Nagai T, Yamazaki T, Ogata T. A 3-bp deletion mutation of PTPN11 in an infant with severe Noonan syndrome including hydrops fetalis and juvenile myelomonocytic leukemia. Am J Med Genet A 2004;128A:63-6.

13 Cheong JLY, Moorkamp MH. Respiratory failure, juvenile myelomonocytic leukemia, and neonatal Noonan syndrome. J Pediatr Hematol Oncol 2007:29:262-4.

14 Kratz CP, Niemeyer CM, Castleberry RP, Cetin M, Bergsträsser E, Emanuel PD, Hasle H, Kardos G, Klein C, Kojima S, Stary J, Trebo M, Zecca M, Gelb BD, Tartaglia M, Loh ML. The mutational spectrum of PTPN11 in juvenile myelomonocytic leukemia and Noonan syndrome/myeloproliferative disease. Blood 2005;106:2183-5.

15 Niemeyer CM, Kratz CP. Paediatric myelodysplastic syndromes and juvenile myelomonocytic leukaemia: molecular classification and treatment options. $\mathrm{Br} \mathrm{J}$ Haematol 2008:140:610-24.

16 Tartaglia M, Zampino G, Gelb BD. Noonan syndrome: clinical aspects and molecular pathogenesis. Mol Syndromol 2010;1:2-26.

17 Romano AA, Allanson JE, Dahlgren J, Gelb BD, Hall B, Pierpont ME, Roberts AE, Robinson W, Takemoto CM, Noonan JA. Noonan syndrome: clinical features, diagnosis, and management guidelines. Pediatrics 2010;126:746-59.

18 Tartaglia M, Niemeyer CM, Fragale A, Song X, Buechner J, Jung A, Hählen $K$ Hasle $H$, Licht JD, Gelb BD. Somatic mutations in PTPN11 in juvenile myelomonocytic leukemia, myelodysplastic syndromes and acute myeloid leukemia. Nat Genet 2003;34:148-50

19 Pérez B, Kosmider O, Cassinat B, Renneville A, Lachenaud J, Kaltenbach S, Bertrand $Y$, Baruchel $A$, Chomienne C, Fontenay M, Preudhomme $\mathrm{C}$, Cavé $\mathrm{H}$. Genetic typing of CBL, ASXL1, RUNX1, TET2 and JAK2 in juvenile myelomonocytic leukaemia reveals a genetic profile distinct from chronic myelomonocytic leukaemia. Br J Haematol 2010;151:460-8.

20 Keilhack H, David FS, McGregor M, Cantley LC, Neel BG. Diverse biochemical properties of Shp2 mutants. Implications for disease phenotypes. J Biol Chem 2005:280:30984-93.

21 Tartaglia M, Martinelli S, Stella L, Bocchinfuso G, Flex E, Cordeddu V, Zampino G, Burgt IV, Palleschi A, Petrucci TC, Sorcini M, Schoch C, Foa R, Emanuel PD, Gelb BD. Diversity and functional consequences of germline and somatic PTPN11 mutations in human disease. Am J Hum Genet 2006;78:279-90.

22 Martinelli S, Torreri P, Tinti M, Stella L, Bocchinfuso G, Flex E, Grottesi A, Ceccarini M, Palleschi A, Cesareni G, Castagnoli L, Petrucci TC, Gelb BD, Tartaglia M. Diverse driving forces underlie the invariant occurrence of the T42A, E139D, I282 V and T468M SHP2 amino acid substitutions causing Noonan and LEOPARD syndromes. Hum Mol Genet 2008:17:2018-29.

23 Schubbert S, Shannon K, Bollag G. Hyperactive Ras in developmental disorders and cancer. Nat Rev Cancer 2007:7:295-308.

24 Van der Burgt I. Noonan syndrome. Orphanet J Rare Dis 2007;2:4.

25 Keren B, Hadchouel A, Saba S, Sznajer Y, Bonneau D, Leheup B, Boute O, Gaillard D, Lacombe D, Layet V, Marlin S, Mortier G, Toutain A, Beylot C, Baumann C, Verloes A, Cavé H; French Collaborative Noonan Study Group. PTPN11 mutations in patients with LEOPARD syndrome: a French multicentric experience. J Med Genet 2004;41:e117.

26 Cambier N, Menot ML, Schlageter MH, Balitrand N, Leblanc T, Bordigoni $\mathrm{P}$ Rohrlich P, Lamagnère JP, Donadieu J, Herbelin C, Puissant C, Gourand F, Baruchel A, Chomienne C. All trans retinoic acid abrogates spontaneous monocytic growth in juvenile chronic myelomonocytic leukaemia. Hematol J Off J Eur Haematol Assoc EHA 2001:2:97-102. 
27 Allen RC, Zoghbi HY, Moseley AB, Rosenblatt HM, Belmont JW. Methylation of Hpall and Hhal sites near the polymorphic CAG repeat in the human androgen-receptor gene correlates with X chromosome inactivation. Am J Hum Genet 1992;51:1229-39.

28 Swierczek SI, Piterkova L, Jelinek J, Agarwal N, Hammoud S, Wilson A, Hickman K, Parker CJ, Cairns BR, Prchal JT. Methylation of AR locus does not always reflect $X$ chromosome inactivation state. Blood 2012;119:e100-109.

29 Bertelsen $B$, Tümer Z, Ravn K. Three new loci for determining $x$ chromosome inactivation patterns. J Mol Diagn JMD 2011;13:537-40.

30 Bolduc V, Chagnon P, Provost S, Dubé M-P, Belisle C, Gingras M, Mollica L, Busque $L$. No evidence that skewing of $X$ chromosome inactivation patterns is transmitted to offspring in humans. J Clin Invest 2008:118:333-41.

31 Giovannini L, Cavé $H$, Ferrero-Vacher C, Boutte P, Sirvent N. A new PTPN11 mutation in juvenile myelomonocytic leukaemia associated with Noonan syndrome. Acta Paediatr 2005;94:636-7.

32 Tartaglia M, Martinelli S, lavarone I, Cazzaniga G, Spinelli M, Giarin E, Petrangeli V, Carta C, Masetti R, Aricò M, Locatelli F, Basso G, Sorcini M, Pession A, Biondi A. Somatic PTPN11 mutations in childhood acute myeloid leukaemia. Br J Haematol 2005;129:333-9.
33 Timeus F, Crescenzio N, Baldassarre G, Doria A, Vallero S, Foglia L, Pagliano S, Rossi C, Silengo MC, Ramenghi U, Fagioli F, Cordero di Montezemolo L, Ferrero GB. Functional evaluation of circulating hematopoietic progenitors in Noonan syndrome. Oncol Rep 2013;30:553-9.

34 Side LE, Shannon KM. Myeloid disorders in infants with Noonan syndrome and a resident's « rule » recalled. J Pediatr 1997;130:857-9.

35 Becker K, Hughes H, Howard K, Armstrong M, Roberts D, Lazda EJ, Short JP, Shaw A, Patton MA, Tartaglia M. Early fetal death associated with compound heterozygosity for Noonan syndrome-causative PTPN11 mutations. Am J Med Genet A 2007:143A:1249-52.

36 Ekvall S, Hagenäs L, Allanson J, Annerén G, Bondeson M-L. Co-occurring SHOC2 and PTPN11 mutations in a patient with severe/complex Noonan syndrome-like phenotype. Am J Med Genet A 2011;155A:1217-24.

37 Loh ML, Vattikuti S, Schubbert S, Reynolds MG, Carlson E, Lieuw KH, Cheng JW, Lee CM, Stokoe D, Bonifas JM, Curtiss NP, Gotlib J, Meshinchi S, Le Beau MM, Emanuel PD, Shannon KM. Mutations in PTPN11 implicate the SHP-2 phosphatase in leukemogenesis. Blood 2004;103:2325-31.

38 Grossmann KS, Rosário M, Birchmeier C, Birchmeier W. The tyrosine phosphatase Shp2 in development and cancer. Adv Cancer Res 2010;106:53-89. 